\title{
A ADEQUAÇÃO DOS INSTRUMENTOS DE GESTÃO DEMOCRÁTICA NA REVISÃO DO PLANO DIRETOR EM MARABÁ/PA
}

\section{THE ADEQUACY OF DEMOCRATIC MANAGEMENT INSTRUMENTS IN THE REVISION OF THE DIRECTOR PLAN IN MARABÁ / PA}

\section{Daniella Maria dos Santos Dias ${ }^{1}$ \\ Chaira Lacerda Nepomuceno ${ }^{2}$}

\section{Resumo}

Este trabalho objetiva avaliar a adequação dos instrumentos de gestão democrática contidos no projeto de lei de Revisão do Plano Diretor Participativo do Município de Marabá, às disposições do Estatuto da Cidade, e os possíveis avanços em comparação com o Plano Diretor vigente, quanto à missão de criação de um ambiente político-institucional propício ao exercício da democracia participativa. Sob uma metodologia comparativa, realizou-se uma análise qualitativa-descritiva, em formato de estudo de caso. Os institutos analisados foram o 'Sistema de Acompanhamento e Controle do Plano Diretor Participativo'; o 'Conselho Gestor do Plano Diretor'; a implantação dos 'Conselhos Distritais'; a 'Conferência do Plano Diretor' e o 'Sistema de Informações Municipais'. Constatou-se que, na Revisão do Plano Diretor, os institutos pouco avançaram, persistindo sua mera previsão normativa e singela abertura à participação popular. Em especial, quanto ao Conselho Gestor, verificou-se a necessidade de adequar sua composição às disposições do Estatuto da Cidade e a criação de institutos participativos independentes da atuação do conselho, direcionados ao munícipe.

Palavras-chave: Plano Diretor Participativo; Revisão; Gestão Democrática.

\section{Abstract}

This paper aims to evaluate the adequacy of the instruments of democratic management of the Master plan revision process in Marabá, to the provisions of the City Statute, and the progress made in relation to the previous Master Plan, regarding the mission of creating a political-

\footnotetext{
${ }^{1}$ Investigação Pós-Doutoral na Universidade Carlos III de Madri na Espanha, junto ao Departamento de Direito Público Comparado e ao Instituto Pascual Madoz. E-mail: diasdaniella@gmail.com

2 Graduação em Direito na Universidade Federal do Sul e Sudeste do Pará (UNIFESSPA). E-mail: chaira01@gmail.com
} 
institutional environment conducive to the exercise of participative democracy. Using a comparative methodology, a qualitative-descriptive analysis was carried out in a case study format. The institutes analyzed were the 'System of Monitoring and Control of the Participative Master Plan'; the 'Managing Board of the Master Plan'; the implementation of the 'District Councils'; the 'Master Plan Conference' and the 'Municipal Information System'. It was verified that the institutes made a little progress in this Review, persisting its mere legislative provision and simple openness to the popular participation. In particular, as regards the Managing Board, it is necessary to fit to the provisions contained in the City Statute and the establishment of indepent participatory institutes aimed at the citizen.

Keywords: Participative Master Plan; Review; Democratic Management. 


\section{INTRODUÇÃO}

Após 16 anos de promulgação do Estatuto da Cidade (EC) (Lei federal no 10257/2001), muitos municípios brasileiros enfrentam o desafio da primeira revisão do Plano Diretor. Ocorre que o art. 42-A, §40 do EC deu prazo de 5 anos, após a edição da lei, para elaboração do Plano Diretor pelos municípios que ainda não dispunham deste instrumento, bem como instituiu a obrigatoriedade de revisão do plano após 10 anos de vigência.

Este momento é de premente importância para este estudo, que objetiva avaliar a adequação dos instrumentos da gestão democrática do Projeto de Lei (PL) de Revisão do Plano Diretor Participativo do Município de Marabá (PDPMM), às disposições do Estatuto da Cidade, e os avanços em relação ao Plano Diretor vigente, quanto à missão de criação de um ambiente político-institucional propício ao exercício da democracia participativa.

Para justificar a importância deste trabalho, necessita-se apresentar brevemente algumas ponderações quanto ao Plano Diretor vigente do Município de Marabá, Lei municipal no 17.213 de 09 de outubro de 2006, que entrou em processo de revisão no ano de 2017, coordenado pela Secretaria de Planejamento do Município, com recursos próprios e apoio institucional da Universidade Federal do Sul e Sudeste do Estado do Pará (UNIFESSPA) e do Programa Estadual de Ordenamento Territorial Urbano (PROTURB) do Estado do Pará.

Integrando o grupo de pesquisa em "Planejamento Urbano" formado na Universidade Federal do Sul e Sudeste do Pará (UNIFESSPA), Nepomuceno e Dias (2017) publicaram o artigo "O estatuto da cidade e a democratização da gestão urbana: um estudo de caso na cidade de Marabá - PA", tecendo algumas críticas às instâncias participativas do Plano Diretor vigente, por meio da análise documental de atas de reunião do Conselho Gestor deste primeiro.

Em linhas gerais, Nepomuceno e Dias (2017) constataram a baixa representatividade das associações de moradores e bairros na formação do Conselho Gestor do Plano Diretor (CGPD); a necessidade de capacitação dos conselheiros para o exercício de suas atribuições legais, bastante amplas, mas pouco efetivas; e a não efetivação dos Conselhos Distritais representativos dos distritos administrativos da zona rural.

Constatou-se, também, que a precária abertura à participação popular na gestão, aliada à deficiência dos instrumentos para o próprio cidadão deflagrar debates sobre assuntos que lhe afetem ou à sua comunidade, parece ter arrefecido o espírito participativo dos munícipes, somada à incapacidade do poder público municipal de criar condições e um ambiente favorável para instigara participação. 
Quanto à instancia máxima decisória do Conselho Gestor, o evento bianual denominado "Conferência Municipal das Cidades", onde ocorre eleição dos conselheiros do CGPD e a população se reúne para o debate de assuntos relacionados à política urbana, asseverou-se a necessidade de acompanhamento da pauta deliberada no evento por meio de canais de comunicação com a população. Esses canais, que possivelmente seriam supridos pelo Sistema de Acompanhamento e Controle do Plano Diretor e o Sistema de Informações Municipais, que prevê disponibilização de atas de reuniões e documentação que confira transparência à gestão, não foram efetivados.

Em suma, o Plano Diretor vigente limitou-se a transcrever trechos da Lei Federal (EC), e tratou de maneira bastante genérica os institutos jurídicos e urbanísticos. Por exemplo, a despeito da previsão legal, o instituto do IPTU progressivo nunca fora aplicado no município. Também, a título de exemplo (pois não é este o enfoque deste trabalho), os Planos de Zoneamento Ambiental, o Plano Municipal de Desenvolvimento Rural, o Programa de Educação Sanitária e Ambiental, que tinham o prazo de 2 anos para implantação, nunca foram implementados.

Destarte, a precária utilização dos instrumentos da política urbana nesses 10 anos, somada à fragilidade das instâncias participativas já relatada, também recrudesceram a apatia política dos munícipes. Um plano com pouca abertura à participação popular, gerido por um Conselho majoritariamente formado pelo Poder Público, não foi capaz de entusiasmar o espírito participativo do cidadão nos processos decisórios. No mesmo sentido, estudos de Russi (2014), sobre a realidade marabaense, também já advertiam que, relativo à gestão democrática e controle social, o Plano Diretor Participativo do Município de Marabá vigente necessitava avançar bastante em um futuro processo de revisão.

Assim, dando continuidade ao estudo de diagnóstico do Plano Diretor vigente já realizado previamente pelas autoras, emergiu a necessidade de avaliara adequação dos instrumentos da gestão democrática do Projeto de Lei $(\mathrm{PL})$ de Revisão do Plano Diretor Participativo do Município de Marabá (PDPMM), às disposições do Estatuto da Cidade, e os avanços em relação ao Plano Diretor vigente, quanto à missão de criação de um ambiente político-institucional propício ao exercício da democracia participativa. Para a consecução destes objetivos, sob uma metodologia comparativa, realizar-se-á uma análise qualitativadescritiva, em formato de estudo de caso. Este trabalho está estruturado em (1) Introdução, (2) Revisão Bibliográfica, (3) Análise dos dispositivos, (4) Considerações Finais e (5) Referências Bibliográficas. 
Dá-se continuidade, então, com a apresentação de uma breve revisão bibliográfica que fundamenta e embasa estes estudos.

\section{REVISÃO BIBLIOGRÁFICA}

Esta Revisão Bibliográfica está centrada nos desafios para a produção e implementação do Plano Diretor em bases democráticas, e seguirá por eixos principais; inicialmente, apresentando as críticas doutrinárias ao Plano Diretor e as perspectivas de atendimento às funções sociais da cidade e da propriedade com a promulgação do Estatuto da Cidade; em seguida, diante do Estatuto da Cidade (a Lei Regulamentadora do art. 182 da Constituição Federal), expõe-se as dificuldades em implementar os aspectos participativos do Plano Diretor, à luz da realidade da sociedade brasileira; e, finalizando, com as potencialidades da gestão democrática da cidade, por meio da efetivação das instâncias participativas previstas no Plano Diretor.

\section{Da (des) função do Plano Diretor}

Anteriormente à Constituição de 1988, havia um vácuo legislativo no que se refere à política urbana e, a inclusão deste capítulo foi resultado da luta dos movimentos sociais ligados à Reforma Urbana. Assim, o Plano Diretor surge com a missão de cumprir as disposições constitucionais de "ordenar o pleno desenvolvimento das funções sociais da cidade e garantir o bem-estar de seus habitantes", conforme art. 182 da Carta Magna. Este artigo traduz a obrigatoriedade do Plano Diretor e sua função como "instrumento básico da política de desenvolvimento e de expansão urbana", porém clamando a edição de uma Lei com diretrizes gerais, o que ocorreu somente em 2001, com a regulamentação da política urbana por meio da Lei no 10.257 de 2001, o Estatuto da Cidade.

Por isso, ainda em 1999, Flávio Villaça via com desconfiança as discussões em torno do Plano Diretor e questionava por que tanto empenho em discutir algo que não existia (VILLAÇA, 1999). Segundo o autor, o Plano Diretor era reiteradamente discutido no País, há várias décadas, em câmaras municipais, em salas de aula de universidades, em congressos e conferências, em inúmeros órgãos municipais, estaduais e federais, mas que se tratava apenas de "uma criação da razão pura, uma construção mental baseada na idéia (sic) pura e descolada da realidade social" (VILLAÇA, 1999, p. 3). 
As experiências, até então, também não eram boas. Villaça explicou que desde o plano de 1971, para São Paulo, conhecido por PDDI, muitos planos diretores limitavam-se a princípios, objetivos e diretrizes gerais. O autor já previa que, com a abrangência que vinha sendo apregoada por muitos acadêmicos, o Plano Diretor assustaria a maioria de nossos prefeitos, que nele veriam um indesejável constrangimento à sua atuação (VILLAÇA, 1999).

O debate legislativo se acirrava para a regulamentação dos artigos constitucionais, que culminaria com a promulgação do Estatuto da Cidade e, na ocasião, desenvolveu-se no Brasil uma corrente de pensamento, ligada especialmente aos meios imobiliários, que defendia a tese de que as propostas do Plano Diretor deveriam se limitar a políticas, objetivos e diretrizes gerais, de forma a não conter dispositivos autoaplicáveis (VILLAÇA, 1999).

Além disso, o plano diretor representaria uma oportunidade para debater os ditos "problemas urbanos" que a elite brasileira preferia ignorar. Por isso, essa classe propugnava por um plano diretor apenas de princípios gerais, e, com isso, conseguiriam um plano diretor inócuo, resumido a um enorme rol de enunciados de políticas, diretrizes, programas e indicações gerais diversas, que não asseguraria qualquer comprometimento, nem mesmo político (VILLAÇA, 1999).

Explanou Villaça (1999) que a elaboração de vários planos diretores para importantes cidades do país, no início dos anos 90, não conseguiu mobilizar os movimentos populares urbanos, pois o plano diretor tornou-se um instrumento desgastado para os movimentos populares, especialmente os ligados à terra e à habitação.

Não obstante os desapontamentos e as críticas, a promulgação do Estatuto da Cidade, 13 anos após a promulgação da Carta Magna, que regulamentou as disposições constitucionais e estabeleceu prazo para a criação do Plano Diretor, foi recebida com grande entusiasmo pelos pesquisadores, inclusive em âmbito internacional.

Purcell (2014) comentou sobre o avanço legislativo no Brasil ocorrido com a promulgação do Estatuto da Cidade. Afirmou que a lei significou que o Estado brasileiro passou a reconhecer explicitamente que o espaço urbano serve a uma função social complexa, além da sua função econômica. No entanto, alertou, também, que a Lei Federal não procurou avançar para além dos direitos de propriedade, apenas equilibrar os interesses dos proprietários com as necessidades sociais dos habitantes urbanos.

Roy (2009) descreveu o Estatuto da Cidade com esperança. A autora registrou que o movimento pelo "direito à cidade" no Brasil é formalizado no Estatuto da Cidade, uma vez que "objetiva democratizar o acesso à terra e à habitação nas cidades brasileiras, bem como 
democratizar o processo de gestão urbana" (ROY, 2009, p. 135). Para cumprir este propósito, "em vez de propor um modo de gerir o espaço, ele busca alterar os próprios modos pelos quais o espaço produz valor e funciona ao mesmo tempo como uma mercadoria e um bem coletivo" (ROY, 2009, p. 135), representando, assim, um avanço em relação do controle espacial da pobreza.

Ocorre que o Estatuto da Cidade trouxe mudanças profundas para a ordem urbanística, traduzindo-se em mudança de paradigma sobre a visão do plano diretor, que adquiriu nova feição a partir desta lei. Contudo, vale ressaltar que a existência de um planejamento para a cidade não é, por si só, capaz de mitigar os problemas urbanos, se não for orientado para o atendimento às funções sociais da propriedade e da cidade. Rolnik (2006) alerta para o fato de que é comum uma abordagem que atribui a "desordem" nas cidades à "falta de Estado", mas que essa assertiva é falsa. Repetem-se as análises que culpam o Estado por não ter planejado, por não ter política habitacional ou mesmo por ter "se ausentado", porém, é flagrante o quanto o planejamento, a política habitacional e de gestão do solo urbano têm contribuído para construir este modelo de exclusão territorial.

Por isso, o Estatuto da Cidade privilegiou sobremaneira a gestão democrática da cidade, forçando os poderes públicos a incluir a população na definição dos rumos desse planejamento, com o fim de exercer verdadeiro controle social e evitar que apenas determinados grupos se apropriem desse processo.

De tal modo, com a regulamentação da política urbana estabelecida pelo EC, juntamente à exigibilidade do PD, acrescentou-se ao Plano um adjetivo importante. O Plano Diretor passou a ser "participativo", pois instituiu-se a obrigatoriedade de promoção de audiências públicas e debates com a participação da população e de associações representativas dos vários segmentos da sociedade para sua elaboração. Significa dizer que, estabeleceu-se o dever do poder público de criar canais para que a população e as associações representativas possam deliberar sobre os espaços urbanos, mitigando os mecanismos da democracia representativa, e privilegiando a participação direta e semidireta da população na gestão e formulação de políticas públicas para as áreas urbanas (DIAS, 2012).

\section{O planejamento urbano à luz do Estatuto da Cidade}

Nesse interregno temporal entre a inclusão da Política Urbana na Constituição e edição da Lei federal regulamentadora, o Plano Diretor ganhou novas feições. Com a promulgação do 
Estatuto da Cidade, deu-se novo fôlego ao planejamento urbano, emergindo o "Plano Diretor Participativo", sob a égide das diretrizes gerais de gestão democrática da cidade (inc. II, art. 2oㅡ, art. 43-45, EC), consulta prévia à população diante de impactos urbanos (inc. XIII, art. 43-45, EC), entre outras disposições.

Entretanto, "o entusiasmo cedeu lugar a um debate mais cauteloso e crítico sobre os limites do novo Plano Diretor Participativo (PD-P), particularmente numa sociedade tão desigual como a brasileira" (KLINK; DENALDI, 2011, p. 1), desigualdade explícita em cidades divididas

entre a porção legal, rica e com infra-estrutura, e a ilegal, pobre e precária, a população que está em situação desfavorável acaba tendo muito pouco acesso a oportunidades de trabalho, cultura e lazer. Simetricamente, as oportunidades de crescimento circulam no meio daqueles que vivem melhor, pois a sobreposição das diversas dimensões da exclusão incidindo sobre a mesma população fazem com que a permeabilidade entre as duas partes seja muito pequena (ROLNIK, 2006, p. 200).

Constituído este modelo de segregação socioespacial, tornam-se marcantes as relações políticas caracterizadas pela troca de favores e manutenção de apadrinhamentos, um fator limitanteao pleno desenvolvimento de uma democracia verdadeiramente includente (ROLNIK, 2006). Sem embargo, a possibilidade de participação e ampliação de debate a todos os segmentos da sociedade e associações representativas pode ser uma possibilidade para a transformação qualitativa dos espaços urbanos de forma a incluir segmentos sociais hipossuficientes.

Além disso, alertou Rolnik (2009) que,mesmo com o advento do Estatuto da Cidade, os debates públicos sobre temas de política urbana que ocorreram pela primeira vezem várias cidades, trataram-se apenas de procedimento formal em várias delas, cujo objetivo, além do cumprimento da exigência legal, seria de que o município pudesse se credenciar para acessar recursos federais para obras de urbanização. Rolnik (2009, p. 47-8) concluiu que o avanço da Reforma Urbana no Brasil carece da

tessitura de uma nova gramática política alicerçada no fortalecimento de espaços de exercício da democracia direta e controle social - eixos tradicionais de da agenda -, da formulação de um projeto de reforma política e de desenvolvimento do atual modelo federativo de governo e gestão urbana, elementos fundamentais para a consolidação da democracia plena no país.

Avançando nos debates sobre a Lei no 10257/2001, já em uma fase de amadurecimento, em que se ventila a revisão de vários planos no Brasil, Klink e Denaldi (2011), em estudo sobre a Revisão do Plano Diretor de Santo André (SP), questionaram a insuficiência do próprio EC como instrumento transformador das cidades, pois o instrumento legal ainda 
assume a propriedade privada como princípio norteador do uso e da ocupação do solo urbano. Além disso, afirmam que "o plano se caracteriza como plano discursivo, que desempenha a função ideológica de ocultar os reais problemas da maioria urbana, e de elevar os interesses de uma pequena elite a objeto da política urbana" (SANTOS Jr., 2008, p. 145 apud KLINK; DENALDI, 2011, p. 2).

Assim, referem-se à "ilusão da participação popular na elaboração dos planos" em função das "profundas desigualdades existentes no Brasil, que fazem com que a participação popular democrática seja algo de difícil alcance, visto que participação significa, essencialmente, um mínimo de igualdade" (VILLAÇA, 2005, p. 50 apud KLINK; DENALDI, 2011, p. 2).

Desta forma, os debates públicos seriam utilizados pela "minoria dominante" para ocultar as outras formas de pressão sobre os tomadores de decisões políticas, em outras palavras, prestam-se a dar aparência democrática às decisões tomadas sob um jogo desequilibrado de pressões, caracterizado por um pequeno grupo que detém influência e poder sobre as decisões da Administração Pública e os processos participativos servem de simulacro democrático. O que, segundo os autores, demonstra a insuficiência do próprio EC em romper com a trajetória excludente das cidades brasileiras (KLINK; DENALDI, 2011).

Explicam que o modelo de planejamento comunicativo-participativo enfatizou a capacidade transformadora do processo de participação, mas não conseguiu elucidar as estruturas de poder e a dinâmica socioprodutiva que limitaram o alcance efetivo do processo participativo (KLINK; DENALDI, 2011). Portanto,

[...] em função das assimetrias de poder, de capacidade discursiva dos agentes que participam e da sub-representação sistemática dos segmentos mais vulneráveis da sociedade, o planejamento comunicativoparticipativo paradoxalmente não apenas pode reforçar a produção e desapropriação desigual do espaço urbano, mas, em função do seu caráter participativo, pode fazê-lo com maior legitimidade política do que os modelos tecnocráticos de planejamento (PURCELL, 2009 apud KLINK; DENALDI, 2011, p. 3).

Relativo ao estudo de caso do processo de revisão em Santo André, Klink e Denaldi (2011, p. 4) concluíram que a metodologia do Plano Diretor Participativo (PD-P) buscou a construção de consensos progressivos, o que, naturalmente, não eliminou os conflitos. O saldo positivo do PD-P, portanto, é que "o processo transformou-se numa arena privilegiada de disputas pela definição e pela aplicação da função social da propriedade e da cidade" (KLINK; DENALDI, 2011, p. 6). Alertam, contudo, para o fato de que não se deve superestimar a capacidade transformadora da nova geração de Planos Diretores após a aprovação do EC (KLINK; DENALDI, 2011). 
Prieto (2010) apresenta em seus estudos, vários óbices relativos à implantação de instâncias participativas, e cita uma institucionalização demasiada de procedimentos e espaços, caracterizada pelo aparecimento de lideranças "profissionalizadas" e simplificação do debate em torno apenas de poucas questões polêmicas, em detrimento de uma discussão geral sobre o desenvolvimento municipal. Apresenta, ainda, casos em que os processos ditos participativos se resumiram à realização de audiências públicas para apresentação de diagnósticos e dados técnicos, sem qualquer processo de mobilização e capacitação dos atores sociais para entender sua função no processo. Também cita os processos em que a população, aparentemente, não manifestou interesse em participar e opinar, mesmo tendo o Poder Público criado oportunidades (PRIETO, 2010).

Esse cenário está relacionado à ideia que Dahl (2001) expôs, segundo a qual, uma economia capitalista de mercado prejudica seriamente a igualdade política. E, por conseguinte, "cidadãos economicamente desiguais têm grande probabilidade de ser também politicamente desiguais" (DAHL, 2001, p. 175). No ambiente urbano, essa desigualdade se expressa por meio da estreita conexão entre as características de nossas cidades e o padrão de desigualdades prevalecentes na sociedade brasileira (CORIOLANO et al., 2013).

Apesar do que foi exposto, não se pode ignorar que a Constituição cidadã estabeleceu um capítulo dedicado à política urbana no ordenamento jurídico brasileiro, e a regulamentação por meio do Estatuto da Cidade é um marco bastante recente nesse processo de democratização da gestão urbana, em um país notavelmente desigual, de raízes patrimonialistas bastante imbricadas na sociedade. E, "O desenvolvimento das funções sociais da cidade requer a interação de interesses econômicos e políticos de forma que a exclusão, as diferenças e a marginalização sociais sejam dissipadas" (DIAS, 2012, p.22), pois é necessária uma mudança paradigmática para que o exercício do direito de propriedade se dê em cumprimento ao princípio constitucional da função social da propriedade, que tem intrínseca relação com o potencial da gestão democrática.

A própria fragilidade da organização popular em interferir nos processos decisórios, acaba por conferir grande liberdade de ação aos grupos voltados para a obtenção de lucro no ambiente urbano (KOWARICK, 1979), distanciando-se da realização dos princípios constitucionais da política urbana.

Todavia, esse processo "de instauração de práticas democráticas e de cidadania leva anos, até gerações, para obter resultados concretos, estabelecendo uma cultura de participação popular e gestão democrática" (PRIETO, 2010, p. 45). Os óbices são muitos, afinal, "atingir a 
estabilidade democrática não é simplesmente navegar num mar sem ondas; às vezes, significa enfrentar um clima enlouquecido e perigoso" (DAHL, 2001, p. 173).

\section{PLANO DIRETOR E CIDADANIA}

Não obstante as críticas, O EC estabelece as ferramentas e demonstra as potencialidades de uma gestão compartilhada, em direitos e deveres, com o cidadão, que avança à medida que a sociedade compreende a necessidade dessa abertura e os benefícios que se pode gerar para toda a coletividade, para, enfim, superar-se a incapacidade do poder público de programar formas mais racionais de ocupação do solo (KOWARICK, 1979).

E é por meio do Plano Diretor que esse cenário se concretiza. Avritzer (2008) afirma que o Plano Diretor atua com um desenho institucional de ratificação, onde a política urbana é fruto de negociação do poder público com a sociedade civil.

Em contextos mais hostis à participação, Avritzer (2008) aduz que este desenho de ratificação é o mais capaz de anular políticas particularistas em comparação com outros desenhos participativos (orçamento participativo e conselho de políticas), devido à sua baixa dependência do sistema político vigente.

Essa potencialidade do PD se deve ao caminho do direito urbanístico contemporâneo, que se baseia na consensualidade, "materializada em uma administração dialógica, que não impõe a sua vontade, mas sim a constrói" (VIANA, 2014, p. 1). Destarte, "o direito torna-se um direito negociado, fruto da deliberação coletiva" (VIANA, 2014, p. 4). E isso fica claro nos instrumentos do Estatuto da Cidade, que ditam que administração não pode nem deve administrar sozinha e a participação democrática é a garantia de que os instrumentos de política urbana serão direcionados para a promoção do direito à cidade para todos (DIAS, 2012).

Não obstante, necessita-se do "engajamento dos cidadãos e das associações na discussão, na definição de políticas e na fiscalização dos procedimentos urbanísticos, objetivando a transformação dos espaços urbanos" (DIAS, 2012, p. 104), pois é o exercício da cidadania, por meio de uma democracia participativa, a força necessária à formação e transformação da realidade local (DIAS, 2012).

A participação popular é cogente, porquanto,

[...] a negociação das elites tem seus próprios pesos e contrapesos. Os representantes eleitos participam da negociação até o ponto em que são um canal através do qual os desejos, os objetivos e os valores populares entram nas decisões governamentais (DAHL, 2001, p. 129). 
E, são "as iniciativas de democracia participativa buscam romper esse círculo vicioso, resgatando a dimensão pública e cidadã da política" (SADER, 2002, p.659).

Isso porque as instâncias participativas da gestão urbana estão intimamente ligadas ao que se denomina accountability, termo sem tradução exata para a língua portuguesa.

O termo accountability exprime um processo cíclico, em que a abertura da gestão aos princípios da transparência e publicidade, por um lado, aproxima o cidadão da administração, pelo despertar do sentimento de pertença e responsabilização pela coisa pública, e, por outro, coloca o exercício da atividade administrativa em constante avaliação.

Para Rocha et al. (2012), em regimes democráticos, uma das atividades sociais mais importantes consiste em desenvolver formas e instrumentos de accountability, que se traduzem na instituição de processos de avaliação e responsabilização permanente dos agentes públicos, que também permitam aos cidadãos controlar o exercício do poder concedido aos seus representantes e aos servidores públicos em geral. Assim,

o termo accountability abarca a relação entre o administrador público e a sociedade civil, e como administra bens pertencentes à coletividade deve prestar contas, responsabilizando-se pelos seus atos e consequentes resultados obtidos, o que está totalmente vinculado com os valores de um Estado Democrático de Direito (RIBCZUK; NASCIMENTO, 2015, p. 224).

Ocorre que, nas democracias representativas, nada impede, do ponto de vista legal, que os representantes violem os interesses dos seus representados. O controle possível "é a capacidade dos eleitores de exigir que os representantes expliquem o que fazem. Em outras palavras, a única forma de obrigar os representantes a cumprirem as promessas pelas quais foram eleitos é a accountability" (ARATO, 2002apudROCHA et al., 2012, p. 3).

Cidadania e democracia fortalecem a accountability social, "uma importante ferramenta no controle da Administração Pública no gerir as políticas públicas e no direcionar o uso dos recursos públicos" (AMARAL; GUIMARÃES; DAUMERIE, 2015, p. 812). E os mecanismos que a Administração Pública cria e aplica para a observância da boa governança, da governabilidade plena, da accountability e da gestação pública social, nada mais são do que a consolidação do Estado Democrático de Direito (RIBCZUK; NASCIMENTO, 2015) e "alcança os princípios constitucionais de legalidade, impessoalidade, moralidade, publicidade, bem como eficiência, visto que o administrador público deve responder por todos eles" (RIBCZUK; NASCIMENTO, 2015, p. 224).

Da mesma forma, 
o cidadão, como titular da coisa pública, precisa necessariamente estar próximo ao Estado, para que esse tome conhecimento de suas demandas, e as atenda de maneira eficiente, com a prestação de serviços e a redução das desigualdades sociais, visando proporcionar o bem-estar geral da sociedade (RIBCZUK; NASCIMENTO, 2015, p. 222).

A accountability se desdobra, então, em uma dupla obrigação, a dos governantes de prestarem contas de suas ações aos cidadãos que os escolheram; e dos cidadãos, de manterem, uma estreita vigilância sobre o uso do poder concedido aos que foram escolhidos para governálos (ROCHA et al., 2012).

O exercício do poder pelos cidadãos pode ocorrer, então, de diversas maneiras, entre elas: mediante a demanda por informações públicas e seu monitoramento, por meio da manifestação de opiniões e expectativas, por meio da exigência de satisfação dessas expectativas, a partilha na tomada de decisões e o engajamento direto na produção de bens e serviços (ROCHA et al., 2012). No entanto, para ser efetiva, necessita-se de ambiente políticoinstitucional propício, o acesso a informações precisas e confiáveis e a vontade cidadã de participar. E, são as possibilidades de criação deste ambiente político-institucional propício que se propõe analisar a seguir.

\section{ANÁLISE DOS DISPOSITIVOS LEGAIS À LUZ DO EC}

Prossegue-se este estudo de caso com a análise dos institutos presentes no Projeto de Lei PL no 056/2017, que “Dispõe sobre a Revisão do Plano Diretor Participativo do Município de Marabá", que propiciarão a participação democrática e como esses mecanismos de participação sofreram transformações, positivas e negativas, em relação ao PD vigente, e se cumprem a missão de criação de um ambiente político-institucional propício ao exercício da democracia participativa, levando-se em consideração as disposições do EC e a bibliografia consultada. Para este estudo foram selecionados os seguintes institutos: Sistema de Acompanhamento e Controle do Plano Diretor Participativo; Conselho Gestor do Plano Diretor; Implantação dos Conselhos Distritais; Conferência do Plano Diretor e Sistema de Informações Municipais.

Assim, conforme os pressupostos teóricos expostos nas seções anteriores, o Projeto de Lei $(\mathrm{PL})$ de Revisão será analisado por três eixos:

1. Efetivação dos institutos durante a vigência do Plano Diretor anterior: esse primeiro eixo temático é relativo à efetivação dos instrumentos democráticos durante a vigência do Plano Diretor (2006-2017), e tomará por base o prévio estudo de caso de 
Nepomuceno; Dias (2017). Neste trabalho, já estão estruturados esses dados, que fornecerão subsídio à avaliação das transformações sofridas pelo PD nesta Revisão (conforme sintetizado na "Introdução").

2. Atendimento às disposições básicas do Estatuto da Cidade: por conseguinte, este eixo de análise será centrado na comparação entre a nova redação dos instrumentos participativos no PL de Revisão, as disposições mínimas do EC - lei regulamentadora - e o que expõe a doutrina nacional sobre a gestão democrática e o processo de planejamento.

3. Adequação do instrumento à realidade local e superação da descrição genérica: o derradeiro eixo avaliará se a redação dos artigos ultrapassou a mera reprodução dos dispositivos do EC, adequando-se à realidade local, bem como, se a regulamentação no Plano Diretor traça o caminho para possibilitar a real aplicação dos dispositivos, com a devida abertura à participação popular e demonstração de resultados concretos aos munícipes de sua participação.

\section{SISTEMA DE ACOMPANHAMENTO E CONTROLE DO PLANO DIRETOR PARTICIPATIVO}

O Sistema de Acompanhamento e Controle compreende o conteúdo mínimo do Plano Diretor (art. 42, EC). A legislação regulamentadora não detalha no que consiste este "sistema", mas partindo-se do eixo principiológico que estabelece o Estatuto da Cidade (art. 2으), esse Sistema deve conter mecanismos de accountability, de forma a propiciar acesso às informações relativas aos atos de gestão do Plano Diretor com transparência e ampla publicidade, bem como possibilitar o exercício do controle social, culminando na integração entre a sociedade civil e os administradores públicos na definição dos rumos do planejamento urbano. Isso porque, "os mecanismos de controle e fiscalização são condicionados pela transparência e pela visibilidade das ações do poder público" (FIGUEIREDO; SANTOS, 2013, p. 4).

A transparência está relacionada à "informação completa, objetiva e confiável e de qualidade, ao acesso, à compreensão e aos canais totalmente abertos de comunicação" (ALÓ, 2009 apud FIGUEIREDO; SANTOS, 2013, p. 4). Outrossim, "a entidade pública, ao dar transparência de seus atos de forma clara e confiável, permite que os cidadãos verifiquem se tais atos estão atendendo as necessidades da coletividade" (FIGUEIREDO; SANTOS, 2013, p. 10). 
A transparência tem o condão de estimular a participação social, pois a informação divulgada aproxima a sociedade da gestão exercida por seus representantes, constituindo um dever das entidades públicas de promover a transparência de sua administração, e direito da sociedade ao acesso e o acompanhamento da administração pública, como forma de consolidação da cidadania (FIGUEIREDO; SANTOS, 2013).

Nesse sentido, José Carvalho dos Santos Filho apresenta o conceito de controle da Administração Pública como "o conjunto de mecanismos jurídicos e administrativos por meio dos quais se exerce o poder de fiscalização e de revisão da atividade administrativa em qualquer das esferas de Poder" (CARVALHO FILHO, 2017, p. 527). Afirma que, fiscalização e revisão são os elementos básicos do controle, consistindo a fiscalização no poder de verificação sobre a atividade dos órgãos e agentes administrativos em relação à finalidade pública, que deve servir de objetivo para a Administração.

Sendo assim, "os mecanismos de controle vão assegurar a garantia dos administrados e da própria Administração no sentido de ver alcançados esses objetivos e não serem vulnerados direitos subjetivos dos indivíduos nem as diretrizes administrativas" (CARVALHO FILHO, 2017, p. 527). Uma vez que, é através do controle que os administrados e a Administração podem aferir a legitimidade ou a conveniência das condutas administrativas, representando, os mecanismos de controle, verdadeira garantia para ambos (CARVALHO FILHO, 2017).

Controle, contudo, é gênero do qual o controle social figura como espécie, que significa o exercício de um controle exógeno do Poder Público nascido das diversas demandas dos grupos sociais, com imenso potencial democratizante, permitindo a efetiva participação dos cidadãos em geral no processo de exercício do poder. Carvalho Filho (2017) cita que a efetivação do controle social pode ocorrer de duas formas. Uma pelo controle natural, executado diretamente pelas comunidades, através dos próprios indivíduos que as integram, por meio de entidades representativas, como associações, fundações, sindicatos e outras pessoas do terceiro setor e, de outro lado, o controle institucional, exercido por entidades e órgãos do Poder Público instituídos para a defesa de interesses gerais da coletividade (CARVALHO FILHO, 2017).

Do exposto, extrai-se a natureza do sistema de acompanhamento e controle e verificase que é o controle social natural que o EC visa fomentar.

Adentrando a realidade local, o Sistema de Acompanhamento e Controle está definido no texto da Revisão do PD em Marabá (art. 196) como "conjunto de estruturas e processos democráticos participativos cuja finalidade é assegurar a elaboração, a revisão, a 
operacionalização do planejamento e gestão municipal, de forma integrada, contínua, dinâmica, ascendente e participativa", determinação legal que se coaduna aos ensinamentos de Barros; Carvalho; Montandon (2011, p. 54), em seu "Estatuto da Cidade Comentado", de que o Plano Diretor "deve ser concebido como um processo político de tomada de decisões sobre a gestão do território municipal, que envolva toda a sociedade".

Pois que, para os autores "o Plano Diretor é a instância de integração das políticas setoriais no âmbito do planejamento e do ordenamento de todo o território" (BARROS; CARVALHO; MONTANDON, 2011, p. 54). E a formação desse sistema deve ser orientada para o fato de que o Plano Diretor precisa influenciar os orçamentos municipais e os investimentos públicos, "sendo definidas diretrizes que devem ser seguidas nos planos plurianuais, nos orçamentos anuais e nos demais programas, planos e projetos setoriais municipais" (BARROS; CARVALHO; MONTANDON, 2011, p. 54).

Com este objetivo, a composição do Sistema em Marabá é mista, formado pela Sociedade Civil e Poder Público. Além das secretarias do município, as instâncias participativas do Plano Diretor colacionadas abaixo também o compõe:

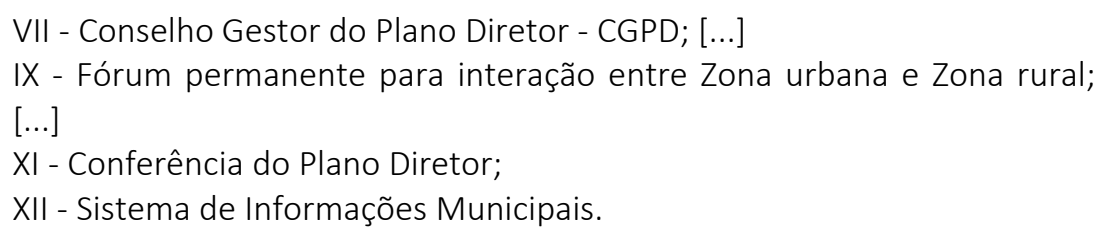

Ocorre que, os estudos prévios de Nepomuceno e Dias (2017) já demonstraram que o Sistema de Acompanhamento e Controle se mostrou inócuo sob o PD vigente, pois não havia qualquer registro documental de suas ações, nem mesmo foi documentada qualquer contribuição à gestão do Plano. Por isso, quanto ao primeiro eixo avaliado (efetivação do instituto durante a vigência do Plano Diretor anterior), verificou-se que o Sistema não apresentou resultados práticos, além de sua definição legal.

Sua inefetividade obsta a consecução dos fins últimos da política urbana, da função social da propriedade e da cidade e, se percebe que, mesmo com a Revisão, o Sistema continua prevendo objetivos bastante abstratos, difíceis de mensurar quanto ao atendimento, e de individualizar, quanto à atuação do próprio Conselho Gestor do Plano Diretor.

No contexto do Projeto de Lei da revisão, este instrumento sofreu alteração legislativa apenas para inclusão de secretarias, conforme transcrição abaixo:

III - Serviço de Saneamento Ambiental de Marabá - Ambiental Saneamento - SSAM;

IV - Secretaria Municipal de Meio Ambiente - SEMMA;

V - Secretaria Municipal de Viação e Obras Públicas - SEVOP; 
VI - Agência Municipal de Regulação de Serviços Públicos de Marabá ARSEMA;

IX - Fórum permanente para interação entre Zona urbana e Zona rural;

Quanto ao segundo eixo analisado, tem-se que sua previsão normativa atende ao disposto na Lei Regulamentadora, conforme explicitado acima. Mas, conforme o terceiro eixo de análise, tratando-se do texto vago e abstrato do capítulo relativo ao Sistema de Acompanhamento e Controle, que mantém a mesma estrutura que não deu certo no PD anterior, a tendência é prosseguir com uma previsão normativa que não tem possibilidade de ganhar efetividade.

Contudo, havendo vontade política do Poder Público em efetivar essa instância participativa, ativando-a na vigência deste novo plano, poderá, então, assumir sua verdadeira vocação de integração Poder Público-Sociedade Civil, com vistas ao exercício do controle social e possibilidade de que os dispositivos normativos tenham plena penetração na realidade social.

\section{SISTEMA DE INFORMAÇÕES MUNICIPAIS}

O Sistema de Informações Municipais, na mesma toada do Sistema de Acompanhamento, tem o condão de prover transparência e publicidade nos atos de gestão e orientar, assim, a tomada de decisões. O Sistema de Acompanhamento e Controle deveria consistir na integração física de secretarias municipais, entes públicos e sociedade civil; enquanto o Sistema de Informações, cumpriria a operacionalização do acompanhamento e controle, na forma de uma ferramenta institucional.

Conforme se extrai de sua definição legal, no art. 210 do PDPMM, o sistema de informações municipais tem "o objetivo de fornecer informações para o planejamento, o monitoramento, a implementação e a avaliação da política urbana e territorial sustentável, subsidiando a tomada de decisões ao longo do processo". No parágrafo único, acrescenta que "deverá conter e manter atualizados dados, informações e indicadores sociais, culturais, econômicos, financeiros, patrimoniais, administrativos, físico-territoriais, inclusive cartográficos, ambientais, imobiliários e outros de relevante interesse para o município".

Da redação do art. 211, tem-se que o Sistema de Informações Municipais deverá obedecer aos princípios:

I - Da simplificação, economicidade, eficácia, clareza, precisão e segurança, evitando-se a duplicação de meios e instrumentos para fins idênticos; 
II - Democratização, publicidade e disponibilidade das informações, em especial as relativas ao processo de implementação, controle e avaliação do Plano Diretor e da Política Habitacional de Interesse Social.

Durante a vigência do Plano Diretor (2006-2017), o Sistema de Informações Municipais esteve inoperante, conforme constatado por Nepomuceno e Dias (2017), em resposta à análise do primeiro eixo.

Nesta Revisão, a redação do dispositivo manteve-se inalterada. Contudo, sua previsão legal atende ao disposto no EC, em alusão ao segundo eixo de análise deste estudo:

Art. 40. § 40 No processo de elaboração do plano diretor e na fiscalização de sua implementação, os Poderes Legislativo e Executivo municipais garantirão:

II - a publicidade quanto aos documentos e informações produzidos;

III - o acesso de qualquer interessado aos documentos e informações produzidos.

Em meados de 2017, a Prefeitura Municipal de Marabá instituiu no sítio <http://www.gdic.com.br/modulo/esic/login/4466490 \o e-SIC, "Sistema Eletrônico do Serviço de Informações ao Cidadão". O e-SIC permite que qualquer pessoa, física ou jurídica, encaminhe pedidos de acesso à informação, acompanhe os prazos de atendimento à solicitação e receba uma resposta. Segundo descrição no sítio, o cidadão ainda pode entrar com recursos e apresentar reclamações, sem burocracia. Pode-se inferir que o sistema está pouco difundido entre os munícipes, dada à baixa quantidade de pedidos de informação já registrados (apenas 35), até dezembro de 2017.

Vale observar que o município também atende às disposições da LC № 131, existindo o Portal da Transparência <http://www.governotransparente.com.br/4466490>. Essa Lei Complementar, que alterou a redação da Lei de Responsabilidade Fiscal, no que se refere à transparência da gestão fiscal, inova ao disponibilizar, em tempo real, informações pormenorizadas sobre a execução orçamentária e financeira da União, Estados, DF e Municípios.O portal se encontra estruturado em Receitas; Despesas; Despesas com Pessoal; Despesas com Diárias; Despesas com obras; Recursos Federais Recebidos; Contratos; Convênios; Fornecedores; Lista de Fornecedores; Licitações; Estrutura Organizacional; Programas; ações e projetos; legislação municipal; gestores; outras informações; E-SIC; ouvidoria; e gestão fiscal. Consultando os links disponíveis, pode-se verificar que o Portal está alimentado com informações atuais.

No que tange ao planejamento municipal, estão disponíveis no sítio do Portal da Transparência as seguintes leis: LAI - Lei Municipal no 17.808 de 14 de novembro de 2017; Lei Complementar no 08 de 22 de setembro de 2017 (Código Tributário Municipal); Lei Orgânica 
Municipal de Marabá, texto consolidado atualizado até a Emenda à Lei Orgânica n.ㅇ 49, de 23 de setembro de 2015; Lei Orçamentária Anual - LOA 2013/2014/2015/2016/2017, Lei de Diretrizes Orçamentária - LDO 2013/2014/2015/2016/2017/2018 e Plano Plurianual 2014/2017.

Ocorre que, de acordo com a sua definição legal, existe uma previsão de ampla gama de informações a serem disponibilizadas no sistema de informações municipais. Logo, sob a ótica do terceiro eixo, quanto à adequação do instrumento à realidade local e superação da descrição genérica, o estilo implantado de "informação sob demanda" é insuficiente para atender o que foi proposto e demonstra que o Município ainda está "engatinhando" quanto à publicidade e transparência de seus atos, não implantando a ferramenta de maneira satisfatória, de forma a viabilizar a transparência por meio do acesso à informação e com a abrangência que foi prevista legalmente.

\section{CONSELHO GESTOR DO PLANO DIRETOR}

O Conselho Gestor (CG) está definido no Projeto de Lei da revisão como "órgão consultivo e deliberativo em matéria de natureza urbanística, política urbana, territorial e habitacional, constituído por representantes do Poder Público e da sociedade civil". O CG tem uma imensa lista de atribuições:

Art. 201. O Conselho Gestor do Plano Diretor tem as seguintes atribuições:

I - Acompanhar a implementação do Plano Diretor Participativo, analisando e deliberando sobre questões relativas à sua aplicação, monitoramento e revisão;

II - Acompanhar a execução de planos, programas e projetos de interesse do desenvolvimento urbano, territorial, habitacional e planos setoriais;

III - Convocar, organizar e coordenar as audiências públicas, conferências, assembléias temáticas e territoriais;

IV - Propor à Conferência do Plano Diretor regimentos internos, planos, programas e projetos de interesse urbano e territorial sustentável;

$\checkmark$ - Opinar sobre projetos de leis de interesse da política urbana e territorial municipal, Lei do Plano Diretor, Lei do Plano Plurianual, Lei de Diretrizes Orçamentárias e Lei Orçamentária Anual, antes de seu encaminhamento à Câmara Municipal;

VI - Acompanhar a implementação da Política, Programas e Projetos de Habitação de Interesse Social;

VII - Monitorar a concessão de Outorga Onerosa do Direito de Construir e a aplicação da transferência do direito de construir;

VIII - Aprovar e acompanhar a implementação de Operações Urbanas Consorciadas;

IX - Opinar sobre os projetos de parcelamentos urbanos submetidos à aprovação dos órgãos municipais competentes; 
X - Acompanhar a implementação dos demais instrumentos urbanísticos; XI - Deliberar sobre as omissões e casos não perfeitamente definidos pela legislação urbanística municipal;

XII - Ter acesso a todas as informações da administração municipal, em tempo hábil, necessárias ao cumprimento de suas atribuições;

XIII - Elaborar e aprovar o regimento interno para seu funcionamento, devendo o mesmo ser homologado por meio de Decreto expedido pelo Chefe do Poder Executivo;

XIV - Regulamentar através de Resoluções, os procedimentos internos, os atos normativos e os casos omissos não previstos nesta Lei;

$\mathrm{XV}$ - Facilitar o acesso da população do município a documentos, planos e projetos elaborados pelo Poder Executivo e Legislativo, referentes à política urbana do município;

XVI - Supervisionar e fiscalizar a aplicação dos recursos do Fundo Municipal de Gestão do Plano Diretor Participativo de Marabá - FMPDP;

Houve pouca modificação nas atribuições do Conselho. Contudo, uma importante atribuição que constava do Plano anterior, de "aprovar a Política, Programas e Projetos de Habitação de Interesse Social", foi reduzida apenas a missão de acompanhar a implementação da Política, Programas e Projetos de Habitação de Interesse Social:

Art. 201. O Conselho Gestor do Plano Diretor tem as seguintes atribuições:

$[\ldots]$

VI - Acompanhar a implementação da Política, Programas e Projetos de Habitação de Interesse Social.

Em outras palavras, tem-se que a pequena parcela constituinte do CGPD, representativa dos munícipes, perdeu uma importante atribuição de definir os rumos dos programas de Habitação de Interesse Social.

Acrescentou-se no inciso XIV a atribuição de "Regulamentar através de Resoluções, os procedimentos internos, os atos normativos e os casos omissos não previstos nesta Lei". E, no inciso XVI, mudou-se a nomenclatura do "Fundo Municipal de Desenvolvimento Urbano e de Habitação de Interesse Social" para "Fundo Municipal de Gestão do Plano Diretor Participativo de Marabá - FMPDP" e, ainda, excluiu-se a atividade de aprovação do relatório anual de execução físico-financeiro dos recursos, para restar apenas as atribuições de supervisão e fiscalização.

Desde os estudos prévios destas autoras, já se percebia que toda a atividade do Plano Diretor estava centrada no Conselho e seu poder decisório. Contudo, depreendeu-se da análise documental, que as atividades realizadas estavam bem aquém de suas atribuições, bastante amplas. Verificou-se, pois, que o conselho estava em funcionamento, contudo, havia a necessidade de capacitação dos conselheiros para o exercício de suas atribuições legais. 
Além disso, persiste a crítica quanto à sua composição e abertura à participação popular. As imensas atribuições do CGPD seriam absolutamente louváveis, se houvesse maior abertura à participação popular em sua composição, e se existissem mecanismos autônomos de iniciativa popular para deflagrar debates, independentes do conselho, o que não foi previsto no Plano Diretor vigente, tampouco no Projeto de Lei de Revisão.

O Plano Diretor continua não prevendo qualquer intervenção autônoma dos munícipes na gestão do Plano. Ocorre que

Na luta para superar a enorme desigualdade social que caracteriza as cidades brasileiras, o processo participativo passa a ser uma instância política de disputa por investimentos e de pactuação de um planejamento urbano que considere o lugar dos pobres na cidade. É uma maneira de propiciar a população de baixa renda, sempre excluída do planejamento das cidades, a participar das decisões sobre a regulação do uso e ocupação do território e a destinação dos investimentos públicos (BARROS; CARVALHO; MONTANDON, 2011, p. 56).

$E$, quanto à formação do conselho, houve apenas uma pequena mudança em sua composição. No Plano Vigente estão previstos 15 (quinze) representantes do Poder Executivo Municipal e seus respectivos suplentes. Na Revisão estão previstos 14 (catorze), com a exclusão de 01 (um) Representante da Secretaria Municipal de Assistência Social e 01 (um) Representante da Secretaria de Cultura, Desporto e Lazer e acréscimo de 01 (um) Representante da Serviço de Saneamento Ambiental de Marabá - Ambiental Saneamento e 01 (um) Representante indicado pelo Poder Legislativo Municipal, exceto vereador.

A existência do Conselho atende à disposição do art. 43, de formação de "I - órgãos colegiados de política urbana, nos níveis nacional, estadual e municipal". Entretanto, quanto ao disposto no art. 45 do EC, quando diz "Os organismos gestores das regiões metropolitanas e aglomerações urbanas incluirão obrigatória e significativa participação da população e de associações representativas dos vários segmentos da comunidade, de modo a garantir o controle direto de suas atividades e o pleno exercício da cidadania", ainda existe a necessidade de aumento da participação popular.

Entende-se que a formação centrada em representantes do Poder Público, no caso de Marabá, em percentual de 50\% (cinquenta por cento) da composição, e apenas 13,33\% (treze inteiros e trinta e três décimos percentuais) de representantes das associações de moradores e centros comunitários destoa da "significativa participação da população" que a Lei estabelece e o Texto Constitucional determina.

Comparando-se, Planos Diretores de outros municípios, como o de Florianópolis, por exemplo, o percentual de participação do Poder Público é de 40\% (quarenta por cento). Em 
Jundiaí, tem-se apenas 33,33\% (trinta e três inteiros e trinta e três décimos percentuais) de composição do Conselho Gestor por representantes da Administração. Esse número é de 40,6\% (quarenta inteiros e sessenta décimos percentuais) em Curitiba. Portanto, quanto ao segundo eixo analisado, depreende-se que a existência do Conselho não atende aos requisitos do art. 45 do EC.

Quanto ao terceiro eixo - adequação à realidade local, com possibilidades fáticas de implantação na gestão urbana, abertura à iniciativa popular e demonstração de resultados concretos aos munícipes de sua participação -entende-se que, a partir do atendimento ao disposto no art. 45 do EC, com uma possível ampliação das vagas de conselheiros destinadas aos munícipes, o Conselho se tornaria um instrumento participativo na gestão do município de grande potencial, devido ao extenso rol de atribuições previsto no Plano Diretor.

\section{CONSELHOS DISTRITAIS}

Os Conselhos distritais visam a integração entre zonas rural e urbana, conforme definição. A formação dos Conselhos Distritais recebeu uma nova nomenclatura na Revisão, agora denominado "Fórum Permanente para interação entre Zona Urbana e Rural".

Outrora, o Conselho carecia de atribuições legais, a ser regulamentado por um regimento interno discutido e aprovado pela Assembleia Regional e pelo Conselho Gestor do Plano Diretor, o que nunca ocorreu. No capítulo que tratava dos "Conselhos Distritais", previase também a criação de comitês de gestão de micro bacias hidrográficas (art. 157, PDPMM), previsão esta que não se concretizou e nem existe mais na Revisão.

A respeito do primeiro eixo da análise, repise-se que o Conselho Distrital nunca foi instalado. A revisão repete a estratégia de prever a criação de um Conselho, que já nascerá esvaziado de atribuições legais, sem definir um escopo de atuação e prazos para o seu exercício.

A existência formal do Fórum Permanente para interação entre Zona Urbana e Rural (antigo Conselho Distrital) vem preencher a diretriz geral do art. 2 do EC, segundo o qual:

Art. 2‥ A política urbana tem por objetivo ordenar o pleno desenvolvimento das funções sociais da cidade e da propriedade urbana, mediante as seguintes diretrizes gerais: [...] VII - integração e complementaridade entre as atividades urbanas e rurais, tendo em vista o desenvolvimento socioeconômico do Município e do território sob sua área de influência", em consonância com o EC. 
Contudo, em relação à superação da descrição genérica e adequação à realidade local, eixo 03, este Projeto de Lei de Revisão se absteve de detalhar a sua atuação, composição e atribuições, de forma que, poderá estar fadado ao mesmo destino do antigo Conselho Distrital.

\section{CONFERÊNCIA MUNICIPAL DAS CIDADES}

Barros; Carvalho; Montandon (2011) explicam que um dos elementos fundamentais do Estatuto da Cidade é a promoção da participação da sociedade na gestão urbana e que as decisões sobre o futuro das cidades não podem se limitar somente à democracia representativa das câmaras de vereadores, mas devem propiciar que todos aqueles diretamente afetados pelas ações e investimentos públicos sejam envolvidos. Frisam que

não se trata apenas de consulta a opinião da população sobre as
proposições do Poder Público Municipal, mas de garantir instancias
efetivamente consultivas e deliberativas, tanto no processo de
planejamento urbano, quanto na destinação dos recursos públicos"
(BARROS; CARVALHO; MONTANDON, 2011, p. 56).
ssas possibilidades, o Estatuto da Cidade trouxe diversos instrumentos E, explorando essas possibilidades, o Estatuto da Cidade trouxe diversos instrumentos
para democratizar a gestão da cidades, buscando propiciar a participação da população nos processos decisórios, impedindo que as cidades sejam resultado de um modelo desejado apenas por alguns que detêm o poder econômico capaz de influenciar as decisões políticas (BARROS; CARVALHO; MONTANDON, 2011). No contexto da gestão democrática da cidade, segundo os artigos 40, 43 e 44 do EC, a promoção de conferências municipais atende estes objetivos:

Art. 40. O plano diretor, aprovado por lei municipal, é o instrumento básico da política de desenvolvimento e expansão urbana.

$[\ldots]$

$\S 40$ No processo de elaboração do plano diretor e na fiscalização de sua implementação, os Poderes Legislativo e Executivo municipais garantirão: I - a promoção de audiências públicas e debates com a participação da população e de associações representativas dos vários segmentos da comunidade;

Art. 43. Para garantir a gestão democrática da cidade, deverão ser utilizados, entre outros, os seguintes instrumentos:

[...]

III - conferências sobre assuntos de interesse urbano, nos níveis nacional, estadual e municipal;

Art. 44. No âmbito municipal, a gestão orçamentária participativa de que trata a alínea $f$ do inciso III do art. 40 desta Lei incluirá a realização de debates, audiências e consultas públicas sobre as propostas do plano plurianual, da lei de diretrizes orçamentárias e do orçamento anual, como condição obrigatória para sua aprovação pela Câmara Municipal. 
Em Marabá, existe a previsão de uma conferência de frequência bianual, na qual ocorre a eleição e posse de conselheiros do CGPD, com participação da sociedade civil, a Conferência Municipal da Cidade. O Art. 206 do PDPMM aduz que "A Conferência do Plano Diretor é a instância máxima de decisão do Conselho Gestor do Plano Diretor e terá a participação da população". Contudo, Nepomuceno; Dias (2017) já alertaram para o fato de que a realização de conferências, que não retornam à população o resultado da participação, arrefecem o espírito participativo, em vez de cultivá-lo. E é o que foi diagnosticado em Marabá.

A realização da Conferência não dispõe de uma sistemática de acompanhamento das pautas e deliberações, tornando-se mera formalidade restrita a eleger e empossar os conselheiros do CGPD. Portanto, quanto à primeira análise (efetivação dos institutos durante a vigência do Plano Diretor anterior), verificou-se que apesar de existente, o Poder Público necessitava aperfeiçoar este instrumento, de maneira a acompanhar a pauta da Conferência e fornecer um feedback quanto à participação da população.

Conforme mencionado, a existência do instituto atende à exigência da Lei regulamentadora. Contudo, quanto ao eixo 03 , relativo à sua adequação à realidade local e superação da descrição genérica, o Projeto de Lei de revisão manteve a mesma estrutura do PD vigente, sem prever o necessário feedback à população, o que é agravado pela inoperância do próprio sistema de informações (conforme já relatado), tornando a Conferência um instituto formal, que não possibilita o exercício do potencial participativo com a necessária transparência, publicidade dos atos e demonstração de resultados.

\section{CONSIDERAÇÕES FINAIS}

A Política Urbana no país foi estudada nesse trabalho sob a influência de três grandes marcos: a promulgação da Constituição de 1988, que culminou com a obrigatoriedade do Plano Diretor; a edição do Estatuto da Cidade e este momento, em que vários municípios passam pela primeira revisão obrigatória de seus planos diretores.

Sintetizou-se que, neste caminho entre a obrigatoriedade de formalização do Plano Diretor e a obrigatoriedade de sua Revisão, vários percalços surgiram, obstando a implantação de uma verdadeira democracia participativa nos municípios brasileiros. A efetivação do Plano Diretor, nos moldes do EC, ainda necessita enfrentar entraves políticos, estruturais, teóricos e práticos. 
E, novamente, em incursão sobre a realidade local da gestão do Plano Diretor Participativo de Marabá, intentou-se analisar seus institutos participativos, tendo em vista o processo de Revisão.

Esperava-se que, a oportunidade da Revisão e o amadurecimento ao longo desses 10 anos de vigência do Plano Diretor, se traduzisse em institutos mais robustos, com o aprendizado do que funcionou e o que não funcionou, ao longo desse tempo.

Contudo, o que se observou, foi a continuidade de estruturas que já não foram capazes de incluir a população nos processos decisórios, no passado. Até repetidamente, relatou-se ao longo deste artigo, as falhas observadas na efetivação dos instrumentos participativos durante a vigência do Plano Diretor vigente.

Igualmente, a missão de criação de um ambiente político-institucional propício ao exercício da democracia participativa no âmbito da revisão, também foi frustrada. A saber, o Sistema de Informações Municipais, que influenciaria, sobremaneira, no funcionamento de todas as outras instâncias, pois deveria nutrir a tomada de decisões dos munícipes e dos órgãos gestores do Plano, não atende ao que foi regulamentado no próprio Projeto de Lei de Revisão, nem mesmo fornece o necessário feedback à população relativo à participação.

Esse feedback, especialmente relativo às conferências municipais, que conclamam a participação popular, como a Conferência Municipal da Cidade, é primordial para o ciclo da participação e motivação do munícipe, que se traduz no despertar da accountability.

O Sistema de Acompanhamento e Controle continua representando uma espécie de bis in idem quanto às atribuições do Conselho Gestor, distanciando-se do espirito de integração, cooperatividade e planejamento de curto, médio e longo prazo que deve representar no contexto da gestão urbana.

Por fim, a estrutura do Conselho Gestor permaneceu centrada nos administradores públicos, com baixa participação dos bairros e associações comunitárias, os representantes que são os maiores conhecedores dos problemas locais. Nesse sentido, também persiste a inexistência de previsão legal de instrumentos para iniciativa autônoma do cidadão.

Visando o aprimoramento do processo de Revisão e o compartilhamento do conhecimento produzido no âmbito da Universidade, os resultados destes estudos foram encaminhados ao Conselho Gestor, à equipe de coordenação da revisão e à Secretaria de Planejamento do Município de Marabá. Porém, é entristecedor concluir que se repetiram os mesmos erros, mantendo o afastamento do cidadão do processo decisório. Entende-se, que, o fortalecimento dessas estruturas excludentes demonstra a má vontade política da gestão em 
adequar-se à existência dos instrumentos da democracia direta. Resvala, pois, para o munícipe, a luta para o exercício de sua cidadania, por meio da efetivação dessas instâncias participativas.

\section{REFERÊNCIAS}

AMARAL, C. T. G. GUIMARÃES, M. C. DAUMERIE, R. Democracia participativa brasileira: as audiências públicas como instrumento participativo - a câmara dos vereadores da cidade do Rio de Janeiro. Revista de Direito da Cidade, Rio de Janeiro, v.7, n.2, p. 804-844, jun. 2015.

AVRITZER, L. Instituições participativas e desenho institucional: algumas considerações sobre a variação da participação no Brasil democrático. Opinião Pública, v. 14, n. 1, p. 43-64, jun. 2008.

BARROS, A. M. F. B. CARVALHO, C. S. MONTANDON, D. T. O Estatuto da Cidade Comentado (Lei no10.257 de 10 de julho de 2001). In: BRASIL. Estatuto da Cidade 10 anos: avançar no planejamento e na gestão urbana. Brasília: Senado Federal, gabinete do Senador Inácio Arruda, $2011,66 \mathrm{p}$.

CORIOLANO, G. P. RODRIGUES, W. OlIVEIRA, A. F. Estatuto da Cidade e seus instrumentos de combate às desigualdades socioterritoriais: o Plano Diretor Participativo de Palmas (TO). Revista Brasileira de Gestão Urbana, v. 5, n. 2, p. 131-145, jul. /dez. 2013.

DAHL, R. A. Sobre a Democracia. Brasília: UnB, 2001.

DIAS, Daniella Maria dos Santos. Planejamento e Desenvolvimento Urbano no Sistema Jurídico Brasileiro - Óbices e Desafios. Curitiba: Juruá Editora, 2012.

FIGUEIREDO, Vanuza DA SILVA; SANTOS, Waldir Jorge Ladeira DOS. Transparência e controle social na administração pública. Temas de Administração Pública, v. 8, n. 1, 2013.

KLINK, Jeroen. DENALDI, Rosana. O Plano Diretor Participativo e a produção social do espaço. O caso de Santo André (São Paulo). Scripta Nova, Revista Electrônica de Geografía y Ciencias Sociales, v. XV, n. 382, dez. 2011. 
KOWARICK, Lúcio. A espoliação urbana. Rio de Janeiro: Paz e Terra, 1993.

NEPOMUCENO, Chaira Lacerda. DIAS, Daniella Maria Dos Santos. O estatuto da cidade e a democratização da gestão urbana: um estudo de caso na cidade de Marabá. Revista de Direito da Cidade, v. 9, n. 2, 2017, p. 389-419.

PRIETO, E. C. O plano diretor participativo como instrumento de gestão democrática e fortalecimento do poder local. Fórum de Direito Urbano e Ambiental - FDUA, Belo Horizonte, ano 9, n. 53, p. 40-50, 2010.

PURCELL, Mark. Possible worlds: Henri Lefebvre and the right to the city. Journal of Urban Affairs, v. 36, n. 1, fev. 2014, p. 141-154.

RIBCZUK, Paula. NASCIMENTO, Arthur Ramos do. Governança, governabilidade, accountability e gestão pública: critérios de conceituação e aferição de requisitos de legitimidade. Revista Direito Mackenzie. v. 9, n. 2, p. 218-237, 2015.

ROCHA, Arlindo Carvalho; Spaniol, Enio Luiz. SCHOMMER, Paula Chies; SOUSA, Alessandra Debone de. A coprodução do controle como bem público essencial à accountability. Anais do XXXVI Encontro da ANPAD- ENANPAD, 2012, Rio de Janeiro. Disponível em: <http://www.anpad.org.br/admin/pdf/2012_APB556.pdf>. Acesso em: 19 ago. 2017.

ROLNIK, Raquel. Democracia no fio da navalha limites e possibilidades para a implementação de uma agenda de reforma urbana no Brasil. Revista Brasileira de Estudos Urbanos e Regionais, v. 11, n. 2 2 nov. 2009. Disponível em: <http://www.urbanismo.mppr.mp.br/arquivos/File/2194063PB.pdf>. Acesso em 01 jul. 2016.

ROLNIK, Raquel. A construção de uma política fundiária e de planejamento urbano para o país Avanços e desafios. In: IPEA. Políticas sociais - acompanhamento e análise. n. 12, fev. 2006. Disponível em: $<$ http://ipea.gov.br/agencia/images/stories/pdfs/politicas_sociais/ensaio1_raquel12.pdf>. Acesso em 01 jul. 2017. 
ROY, Ananya. Planejamento e gestão espacial da pobreza. R.B. Estudos urbanos e regionais, v.11, mai. 20019. Disponível em: http://rbeur.anpur.org.br/rbeur/article/view/214/198>. Acesso em 02 jul. 2017.

RUSSI, Anilson. Entre o legal e o real: a regularização fundiária nos assentamentos urbanos informais do município de Marabá. Dissertação (Mestrado). Programa de Pós-Graduação Dinâmicas Territoriais e Sociedade na Amazônia, da Universidade Federal do Sul e Sudeste do Estado do Pará, 2014, 118 p.

SADER, Emir. Para outras democracias. In: SANTOS, B. DE S. (org.). Democratizar a democracia: os caminhos da democracia participativa. Rio de janeiro: Civilização Brasileira, 2002, p. 649-679.

VIANA, C. R. C. A formação concertada de políticas públicas urbanísticas e o exemplo das operações urbanas consorciadas. Revista dos Tribunais Online, São Paulo, v. 5, mar. 2014.

VILLAÇA, Flávio. Dilemas do Plano Diretor. In: O município no século XXI: cenários e perspectivas. ed. especial. São Paulo: Fundação Prefeito Faria Lima - Cepam, 1999, 400 p.

Trabalho enviado em 13 de março de 2018

Aceito em 02 de junho de 2018 